\title{
Efferent Arteriolar Hyalinosis
}

National Cancer Institute

\section{Source}

National Cancer Institute. Efferent Arteriolar Hyalinosis. NCI Thesaurus. Code C96179.

The deposition of hyaline material in the wall of the efferent arterioles. 